\title{
High Volume Sinonasal Budesonide Irrigations for Chronic Rhinosinusitis: An Update on the Safety and Effectiveness
}

\section{Luke Rudmik*}

Division of Otolaryngology-Head and Neck Surgery, Department of Surgery, University of Calgary, Calgary, Alberta, Canada

\begin{abstract}
Chronic rhinosinusitis (CRS) is a common inflammatory disease of the paranasal sinuses associated with severe impairments in patient quality of life, sleep, and productivity. Topical corticosteroid therapy is a key component to a successful management plan for patients with CRS. Delivering topical medical therapies using high-volume sinonasal irrigations are commonly used following endoscopic sinus surgery (ESS) due to its proven efficacy for improving drug delivery into the paranasal sinuses. Topical high volume budesonide irrigations have become a popular offlabel management strategy for CRS with the purpose to improve topical steroid delivery into the sinonasal cavities. Early evidence outlined in this review suggests that high volume sinonasal budesonide irrigations are an effective treatment modality in patients with CRS following ESS. Overall it appears that short-term use of this therapy is likely safe, however, future studies will need to assess the safety of higher doses and longer-term therapy of budesonide irrigations in patients with CRS.
\end{abstract}

Keywords: Chronic rhinosinusitis; Sinusitis; Sinonasal; Nasal; Budesonide; Topical Steroid; Safety; Irrigations; Corticosteroid; Effectiveness

\section{Introduction}

Chronic rhinosinusitis (CRS), otherwise known as chronic sinusitis, is a common inflammatory disease of the paranasal sinuses affecting approximately $7 \%$ to $14 \%$ of the North American population $[1,2]$. Patients with CRS suffer from several detrimental health effects including reduced quality of life (QoL) [3], impaired sleep [4], fatigue [5], acute infections [6], and increased bodily pain [7]. This produces a serious negative impact on society as patients with CRS have substantial productivity costs $(\$ 10,077$ per patient with refractory CRS per year) [8] and large direct medical costs to the health care system. The estimated annual health care expenditure for CRS in the United States (US) is $\$ 8.6$ billion with the majority of costs arising from physician office visits, emergency department encounters, and medication use [9].

Following a correct diagnosis of CRS [10], the accepted primary management strategy begins with medical therapy to reduce mucosal inflammation and improve sinonasal function. Common medical strategies include high-volume isotonic saline irrigations, topical corticosteroid sprays and rinses, short-course systemic corticosteroids and antibiotics, prolonged courses of anti-inflammatory antibiotics (i.e. macrolides), leukotriene pathway modulators, and allergy therapies [11-14]. Endoscopic sinus surgery (ESS) has been shown to offer significant short- and long-term benefit in patients with refractory CRS $[15,16]$. Topical steroids are the preferred maintenance strategy due the reduced risk of potential systemic side-effects with prolonged therapy and increased concentrations applied to the diseased tissue, especially after ESS.

One of the biggest challenges with topical sinonasal medical therapy is the efficiency of delivery into the sinuses in order to adequately treat the underlying mucosal inflammation, especially in the setting of obstructing un-dissected sinus lamellae and potentially obstructing polyps. Attempts to overcome this inherent challenge have resulted in the development of several different delivery techniques. One of the most efficient methods to carry medications into the paranasal sinuses, especially after ESS, is the use of a high-volume sinonasal irrigation ( $>50 \mathrm{ml}$ ) [17-21]. The high-volume delivery technique typically involves mixing an active topical medical agent with an isotonic saline solution followed by a low-pressure delivery into the nasal cavity using either a squeeze bottle or neti pot. Based on a systemic review of the evidence by Thomas et al., it is recommended that a high-volume delivery technique is the optimal delivery technique and should be used in the topical management of patients with CRS, especially after ESS [22].

Topical corticosteroids have proven benefit in the management of CRS [23-25]. Budesonide respules have long been used as a nebulized inhaled topical corticosteroid for patients with asthma [26]. However, due to the ability to mix the budesonide respules (a respule is a small volume $(2 \mathrm{ml})$ single dose vial of liquid corticosteroid) into a high-volume saline device, it has become an increasingly common off-label agent used in the management of CRS. The purpose of this review article is to discuss the evidence pertaining to the safety and effectiveness of off-label high volume budesonide sinonasal irrigations in the management of CRS.

\section{Budesonide Respule: Overview}

Budesonide is a potent topical corticosteroid with an approximately 1,000-fold higher topical anti-inflammatory potency than cortisol Budesonide binds the glucocorticoid receptor and exerts an antiinflammatory effect through several mechanisms including altering the release of arachidonic acid metabolites, inhibiting the accumulation of leukocytes in affected tissue, decreasing vascular permeability, inhibiting neuro-peptide mediated responses, and altering the secretion of glycoproteins from sub-mucosal glands. No studies have defined

*Corresponding author: Luke Rudmik, Division of Otolaryngology-Head and Neck Surgery, Department of Surgery, University of Calgary, Foothills Medical Centre, South Tower suite 602, 1403 - 29th St. NW T2N 2T9, Calgary, Alberta, Canada, Fax: 403-210-8435; E-mail: Lukerudmik@gmail.com

Received February 17, 2014; Accepted April 25, 2014; Published April 28, 2014

Citation: Rudmik L (2014) High Volume Sinonasal Budesonide Irrigations for Chronic Rhinosinusitis: An Update on the Safety and Effectiveness. Adv Pharmacoepidemiol Drug Saf 3: 148. doi:10.4172/2167-1052.1000148

Copyright: (C) 2014 Rudmik L. This is an open-access article distributed under the terms of the Creative Commons Attribution License, which permits unrestricted use, distribution, and reproduction in any medium, provided the original author and source are credited. 
Citation: Rudmik L (2014) High Volume Sinonasal Budesonide Irrigations for Chronic Rhinosinusitis: An Update on the Safety and Effectiveness. Adv Pharmacoepidemiol Drug Saf 3: 148. doi:10.4172/2167-1052.1000148

Page 2 of 5

\begin{tabular}{|c|c|c|}
\hline Company & Approval Date & Budesonide respule products \\
\hline Teva Pharmaceutical Industries Ltd. & November 2008 & $\begin{array}{c}0.25 \mathrm{mg} / 2 \mathrm{ml} \\
0.5 \mathrm{mg} / 2 \mathrm{ml}\end{array}$ \\
\hline ActavisInc & July 2012 & $\begin{array}{l}0.25 \mathrm{mg} / 2 \mathrm{ml} \\
0.5 \mathrm{mg} / 2 \mathrm{ml}\end{array}$ \\
\hline Sandoz Inc. & September 2013 & $\begin{array}{c}0.25 \mathrm{mg} / 2 \mathrm{ml} \\
0.5 \mathrm{mg} / 2 \mathrm{ml} \\
1 \mathrm{mg} / 2 \mathrm{ml}\end{array}$ \\
\hline
\end{tabular}

Table 1: Pharmaceutical companies manufacturing generic budesonide respules.

\begin{tabular}{|c|c|c|c|c|c|c|}
\hline Study & Year & Study Design & LOE & Sample Size & Budesonide Irrigation Protocol & Conclusion \\
\hline $\begin{array}{l}\text { Steinke et al. } \\
\qquad[36]\end{array}$ & 2009 & Prospective - Pilot & 4 & 8 & $\begin{array}{l}\text { High-volume budesonide irrigation } \times 3 \text { months. } \\
\text { Did not specify exact volume, dose, or } \\
\text { frequency }\end{array}$ & $\begin{array}{l}\text { Budesonide may improve patient symptoms and } \\
\text { objective outcomes (CT score and endoscopy) }\end{array}$ \\
\hline $\begin{array}{l}\text { Nader et al. } \\
\text { [33] }\end{array}$ & 2010 & Retrospective & 4 & 71 & $\begin{array}{l}\text { High-volume budesonide irrigation (BID) post } \\
\text { ESS. } \\
\text { Did not specify exact volume or dose. }\end{array}$ & $\begin{array}{l}61 \% \text { of patients complete symptom resolution } \\
\text { with maintenance budesonide irrigation } \\
\text { Non-responders had higher rate of asthma. }\end{array}$ \\
\hline $\begin{array}{l}\text { Rotenberg et } \\
\quad \text { al. [34] }\end{array}$ & 2011 & $\begin{array}{c}\text { RCT } \\
\text { Double-blind } \\
\text { Placebo controlled }\end{array}$ & $1 b$ & 60 & $\begin{array}{l}3 \text { groups post ESS: } \\
\text { 1) High-volume budesonide irrigation ( } 1 \mathrm{mg} \text { in } \\
240 \mathrm{ml} \text { BID) } \\
\text { 2) Saline irrigation + budesonide nasal spray } \\
\text { 3) Saline alone }\end{array}$ & $\begin{array}{l}\text { Budesonide irrigation did not provide additional } \\
\text { benefit compared to saline irrigation alone }\end{array}$ \\
\hline $\begin{array}{l}\text { Snidvongs et } \\
\text { al. [25] }\end{array}$ & 2012 & Prospective & 4 & 111 & $\begin{array}{l}\text { High-volume budesonide irrigation (1 mg in } 240 \\
\text { ml QD) post ESS }\end{array}$ & $\begin{array}{l}\text { 95\% of patients improved with budesonide } \\
\text { irrigations. } \\
\text { Patients with marked tissue eosinophilia received } \\
\text { higher improvements in QoL compared to those } \\
\text { with low tissue eosinophilia. } \\
\text { Patients with ASA sensitivity, asthma, and } \\
\text { polyposis received similar QoL improvements } \\
\text { compared to those without. }\end{array}$ \\
\hline $\begin{array}{l}\text { Jang et al. } \\
\text { [32] }\end{array}$ & 2013 & Retrospective & 4 & 60 & $\begin{array}{l}\text { High-volume budesonide irrigation }(0.5 \mathrm{mg} \text { in } \\
\qquad 88 \mathrm{mls} \text { BID) post ESS }\end{array}$ & $\begin{array}{l}\text { Improvement in disease-specific QoL with } \\
\text { budesonide irrigations }\end{array}$ \\
\hline
\end{tabular}

LOE, level of evidence; CT, computed tomography; BID, twice a day; QD, once a day; RCT, randomized control trial; QoL, quality of life; ml, milliliter; mg, milligram

Table 2: Summary of the evidence on the effectiveness of high-volume budesonide sinonasal irrigations.

the pharmacokinetics of budesonide when delivered to the sinonasal mucosa using high-volume irrigation.

Budesonide respules were developed by Astra Zeneca in 2000 and marketed under the trade name of Pulmicort Respules ${ }^{\oplus}$ (Budesonide inhalation suspension) [27]. The US Food and Drug Administration (FDA) have approved generic versions of Pulmicort respules and there are currently three companies manufacturing generic budesonide respules [28-30] (Table 1). In 2012, Pulmicort Respule ${ }^{\oplus}$ US sales were $\$ 136$ million with an additional \$124 million paid to AstraZeneca in royalties from generic pulmicort sales. In 2018, all patents protecting Pulmicort Respules ${ }^{\oplus}$ will expire.

The FDA approved indication for the budesonide respule is an inhaled agent for the maintenance treatment of asthma and as prophylactic therapy in children 12 months to 8 years of age [31]. When used as off-label sinonasal irrigation, potential adverse effects include local irritation such as nasal burning, nasal dryness, headache, and ear plugging. These local effects have been reported in approximately $23 \%$ of patients and are typically mild in severity [18]. Although rare (as will be discussed in the safety section), there is the potential for systemic absorption and the adverse effects could include adrenal suppression, ocular absorption, reduced bone mineral density, and other corticosteroid effects $[12,31]$. The main mechanism of metabolism for corticosteroids, including budesonide, is through hepatic cytochrome p450 iso-enzyme 3A4 (CYP3A4). Therefore, co-administration of topical budesonide with any CYP3A4 inhibitors (i.e. ketoconazole, itraconazole, and clarithromycin) may raise the systemic exposure to budesonide.

\section{Effectiveness: Budesonide Irrigations}

This review identified 5 studies evaluating the effectiveness of high-volume budesonide sinonasal irrigations (Table 2) [32-36]. The level of evidence was predominantly level 4 , with only one level $1 \mathrm{~b}$ trial evaluating budesonide irrigations in a subset of CRS patients with Samter's Triad (nasal polyposis, asthma, and aspirin sensitivity). In 2009, Steinke et al. published the first study evaluating high volume budesonide sinonasal irrigations in patients with CRS [36]. It was a small-uncontrolled pilot study of 8 patients and after 3 months of treatment, they demonstrated an improvement in both patient-based sinus symptom scores and objective measures (computed tomography (CT) and endoscopy). Furthermore, they demonstrated a trend toward improvements in asthma scores. They concluded that high volume budesonide sinonasal irrigations may produce subjective and objective benefit in patients with CRS.

In 2010, a retrospective study by Nader et al. [33] evaluated 71 patients with medically refractory CRS who have received at least one prior ESS procedure. After implementing high volume budesonide irrigations twice daily, they demonstrated that $61 \%$ of their cohort responded as defined by the absence of symptoms of nasal obstruction or anosmia, with no pus or polyps visible on endoscopy at the last visit. Of the patients who failed to respond to budesonide irrigations, $86 \%$ had asthma and $47 \%$ had aspirin sensitivity. They concluded that the majority of patients respond well to high volume budesonide irrigations and non-responders may have a more severe CRS phenotype.

In 2011, Rotenberg et al. [34] published the only RCT (level 1b) evaluating the clinical effectiveness of high volume budesonide irrigations in patients with CRS. They evaluated a subset of CRS 


\begin{tabular}{|c|c|c|c|c|c|c|}
\hline Study & Year & $\begin{array}{l}\text { Budesonide Irrigation } \\
\text { Protocol }\end{array}$ & $\begin{array}{c}\text { Total Topical } \\
\text { Budesonide Dose }\end{array}$ & $\begin{array}{l}\text { Duration of } \\
\text { Therapy }\end{array}$ & Safety Outcomes & Conclusions \\
\hline Bhalla et al. [41] & 2008 & $\begin{array}{l}1 \mathrm{mg} \text { in } 240 \mathrm{ml} \text { irrigated each } \\
\text { nostril with } 60 \mathrm{ml} \text { twice a day }\end{array}$ & $1 \mathrm{mg}$ per day & 8 weeks & $\begin{array}{l}\text { 1) Morning serum cortisol } \\
\text { levels } \\
\text { 2) АCTH stimulation }\end{array}$ & $\begin{array}{l}\text { No evidence of HPA suppression after } \\
\quad 8 \text { weeks. } \\
\begin{array}{l}\text { Subgroup of patients beyond } 8 \text { weeks } \\
\text { had no HPA suppression }\end{array}\end{array}$ \\
\hline Welch et al. [40] & 2010 & $1 \mathrm{mg}$ in $240 \mathrm{ml}$ twice a day & $2 \mathrm{mg}$ per day & 6 weeks & $\begin{array}{l}\text { 1) Morning serum cortisol } \\
\text { levels } \\
\text { 2) 24-hour urinary cortisol }\end{array}$ & $\begin{array}{l}\text { No evidence of HPA suppression after } \\
6 \text { weeks of therapy }\end{array}$ \\
\hline Seiberling et al. [42] & 2013 & $0.25 \mathrm{mg}$ in $240 \mathrm{ml}$ twice a day & $0.5 \mathrm{mg}$ per day & 4 weeks & Intraocular pressure & No evidence of increase in IOP \\
\hline
\end{tabular}

ACTH, adrenocorticotropic hormone; ml, milliliter; mg, milligram; HPA, hypothalamic pituitary axis

Table 3: Summary of the evidence on safety of high-volume budesonide sinonasal irrigations.

patients with Samter's triad who underwent ESS. Three postoperative treatment groups included saline irrigation alone, budesonide nasal spray, and high volume budesonide sinonasal irrigations (1 mg in 240 mls twice daily). All groups received significant postoperative outcome improvements in disease-specific QoL and endoscopy, however, there was no difference in outcomes between groups. Although this study demonstrated no positive clinical effect of budesonide irrigations, it is important to interpret the findings in the context of CRS patients with Samter's triad.

A recent large series by Snidvongs et al. [35] prospectively evaluated 111 patients receiving either high volume budesonide $1 \mathrm{mg}$ or betamethasone $1 \mathrm{mg}$ (both in $240 \mathrm{mls}$ of saline once daily) sinonasal irrigations following ESS. The results demonstrated that all patients improved with both the budesonide and betamethasone irrigations. Subgroup analysis reported that patients with high tissue eosinophilia $(>10 / \mathrm{HPF})$ received significantly more improvement in disease-specific QoL and endoscopy grading compared to patients with low tissue eosinophilia $(<10 / \mathrm{HPF})$. Furthermore, they demonstrated that there was no difference in improvement between patients with and without polyposis, asthma, or aspirin sensitivity. They concluded high volume budesonide is effective in CRS patients with challenging eosinophilic disease.

The most recent study by Jang et al. [32] retrospectively evaluated 60 patients with CRS who underwent ESS. All patients were treated with postoperative high volume budesonide irrigations $(0.5 \mathrm{mg}$ in 88 mls BID). They used patients as their own controls and compared their disease-specific QoL and endoscopy scores while actively performing budesonide irrigations versus when they stopped for a period longer than 1 month. The results demonstrate that there was a significant worsening in QoL for all CRS subgroups (eosinophilic CRS, Samters triad, and allergic fungal rhinosinusitis) when patients did not use their high volume budesonide irrigations.

In summary, all four level 4 studies evaluating high volume budesonide sinonasal irrigations following ESS have demonstrated clinical improvements in patients with CRS including those with challenging phenotypes such as asthma and aspirin sensitivity. The only study which failed to demonstrate a clinical benefit compared to saline irrigation alone or low volume nasal spray was a small level $1 \mathrm{~b}$ trial evaluating the Samters triad subgroup of CRS. Although the current evidence suggests high volume budesonide irrigations provide benefit in patients with CRS, larger future randomized controlled trials in different CRS subgroups are needed to increase the strength of evidence pertaining to high volume budesonide irrigations.

\section{Safety: Budesonide Irrigations}

Due to the long-term topical therapy required in patients with CRS, maintenance therapies should have an excellent safety profile to minimize patient morbidity. Although there are variable degrees of systemic absorption from topical intranasal steroids, in general the systemic bioavailability as a percentage of administered dose is $<0.1 \%$ for mometasone, $<1 \%$ for fluticasone propionate, $35 \%$ for budesonide, and $44 \%$ for beclomethasone $[37,38]$.

High volume budesonide sinonasal irrigations are used in an offlabel indication, therefore the bioavailability and systemic absorption rates have not been well defined. This creates the potential for undesired systemic corticosteroid absorption as well as potentially unwanted local nasal effects. This section will discuss the evidence on safety surrounding the use of high volume budesonide irrigations.

\section{Hypothalamic-pituitary axis}

It is well known that prolonged exposure to topical corticosteroid carries a theoretic risk of unintended systemic absorption resulting in measurable hypothalamic-pituitary axis (HPA) suppression [39]. This section will review the two studies which have evaluated the safety of high volume budesonide sinonasal irrigations on HPA function (Table 3) $[40,41]$.

In 2008, Bhalla et al. [41] published the first study evaluating the safety of high volume budesonide irrigations in patients with CRS. This was a retrospective study of 18 CRS patients with nasal polyposis who were refractory to standard corticosteroid sprays [41]. All patients received a budesonide irrigation dose of $1 \mathrm{mg}$ in $240 \mathrm{ml}$ of isotonic saline and irrigated each nostril with $60 \mathrm{ml}$ twice a day for a minimum of 8 weeks. The results demonstrated that for an 8 week treatment, there was no evidence of HPA suppression on morning cortisol measurement. Furthermore, of the 7 patients who continued treatment beyond 8 weeks, the adrenocorticotropic hormone (ACTH) stimulation test did not detect any HPA suppression.

In 2010, a study by Welch et al. [40] evaluated the safety of budesonide nasal irrigations in CRS patients following ESS. This was a prospective study of 10 patients receiving a minimum of 6 weeks of $0.5 \mathrm{mg} / 2 \mathrm{ml}$ in $240 \mathrm{ml}$ saline (total of $1 \mathrm{mg}$ dose) twice daily. The results demonstrated that there was no effect on morning serum serum cortisol levels or 24-hour urinary cortisol after 6 weeks of treatment.

Given that high volume delivery techniques, such as squeeze bottle or Neti pot, result in less than $5 \%$ of the solution remaining in the sinuses, the actual concentration of steroid the patient is exposed to is quite low and in fact, may be lower than traditional nasal steroid sprays [17]. This may be one reason why there is no evidence of HPA suppression with high volume budesonide irrigations. Furthermore, both studies had a relatively short time horizon given prolonged duration of budesonide irrigations that patients with CRS require to manage their inflammation. Future studies will require longer followup to improve the safety profile on the HPA of high volume budesonide irrigations. 
Citation: Rudmik L (2014) High Volume Sinonasal Budesonide Irrigations for Chronic Rhinosinusitis: An Update on the Safety and Effectiveness. Adv Pharmacoepidemiol Drug Saf 3: 148. doi:10.4172/2167-1052.1000148

Page 4 of 5

\begin{tabular}{|c|c|c|}
\hline Budesonide irrigation respule mixture & Frequency & Total Daily dose of budesonide \\
\hline Add 1 respule $(2 \mathrm{ml})$ of $0.5 \mathrm{mg} / \mathrm{ml}$ into $240 \mathrm{ml}$ isotonic saline irrigation & BID & $1 \mathrm{mg}$ \\
\hline Add 2 respules $(2 \mathrm{ml}$ each $)$ of $1 \mathrm{mg} / \mathrm{ml}$ into $240 \mathrm{ml}$ isotonic saline irrigation & BID & $2 \mathrm{mg}$ \\
\hline Add 1 respule $(2 \mathrm{ml})$ of $0.25 \mathrm{mg} / \mathrm{ml}$ into $240 \mathrm{ml}$ isotonic saline irrigation & BID & 6 weeks \\
\hline
\end{tabular}

BID, twice a day; ml, milliliter; mg, milligram

Table 4: High-volume sinonasal budesonide irrigation protocols demonstrated to be safe in patients with CRS

\section{Ocular effects}

One of the unwanted signs of systemic corticosteroids is a rise in intraocular pressure (IOP) [39]. A recent study in 2013 by Seiberling et al. [42] evaluated the effect of high volume budesonide nasal irrigation on IOP to determine if there was a risk of this complication. They evaluated two groups of patients receiving $0.25 \mathrm{mg}$ in $240 \mathrm{ml}$ of high volume isotonic saline irrigation twice a day. The first group consisted of 10 patients who received a mean of 6.3 months of budesonide irrigations and the mean IOP for the left and right eyes were $15.9 \mathrm{mmHg}$ and $15.2 \mathrm{mmHg}$, respectively. Only 1 patient from group one had an IOP of greater than $20 \mathrm{~mm} \mathrm{Hg}$ requiring assessment by Ophthalmology. Group two consisted of 8 patients who had IOP measurements before and after budesonide irrigation therapy. After 4 weeks of therapy, there was no difference in pre- and post-treatment IOP measurements. They concluded that high volume intranasal budesonide irrigations given for a period of at least 4 weeks do not appear to increase IOP (Table 3). Although it appears that short-term use of sinonasal budesonide irrigations is safe, future studies with longer follow-up are required to evaluate the ocular safety profile. Table 4 outlines the current high volume sinonasal budesonide irrigation treatment protocols that have evidence to support its safety.

\section{Pregnancy}

Clinicians often encounter the challenge of deciding whether or not to continue high-volume sinonasal budesonide irrigations during pregnancy. Both the patient and the physician must weigh out the benefits of CRS disease maintenance with the potential teratogenic effects, and risk of CRS disease relapse with significant reductions in QoL and other clinical parameters. Since high-volume sinonasal budesonide irrigations are used in an off-label formulation, there have been no formal studies evaluating this treatment modality on the safety in pregnancy. Therefore, all the evidence on safety in pregnancy for budesonide respules are derived from studies evaluating inhaled budesonide. A systematic review performed in 2005 by Gluck et al. [43] concluded that the evidence on intranasal budesonide is limited, but the pharmacological studies show a much lower systemic exposure after intranasal administration. This indicates that the intranasal budesonide safety profile is at least comparable with that of inhaled budesonide therapy.

Inhaled budesonide respules are listed as pregnancy category B which means animal reproduction studies have failed to demonstrate a risk to the fetus and there are no adequate well-controlled studies in pregnant women $[31,44]$. A large population-based study from three Swedish registries covering approximately $99 \%$ of all pregnancies between 1995-1997 demonstrated no increased risk for congenital malformations from inhaled budesonide respules [45]. A study in 2005 by Gluck et al. [43] evaluated over 6,600 infants whose mothers' required inhaled budesonide during pregnancy and concluded that there was no increase risk of congenital malformations.

Overall the evidence suggests that use of high volume budesonide sinonasal irrigations is safe during pregnancy, however, the studies in humans cannot definitively exclude potential harm to the fetus.
Therefore, pregnant mothers and the treating physician must discuss the risks and benefits of continuing therapy and should only be used during pregnancy if clearly needed.

\section{Breast-feeding}

It is common for nursing mothers to inquire about the use of certain medications during breast-feeding. Budesonide is secreted in breast milk and therefore must be considered. Studies evaluating inhaled dry powder budesonide have demonstrated that $0.3 \%$ to $1 \%$ of the total daily dose is excreted in breast milk. There have been no studies evaluating inhaled budesonide respule use during breast-feeding. Therefore, the nursing mother physician should discuss the potential risks of minimal budesonide exposure to the infant with the benefits of CRS disease control before continuing this therapy during breast-feeding.

\section{Conclusions}

Topical corticosteroid therapy is a key component to a successful management plan for patients with CRS. Topical high volume budesonide sinonasal irrigations have gained popularity in the management of CRS, especially following ESS, due to their proven efficacy of penetration into the paranasal sinuses. Early evidence outlined in this review suggests that budesonide irrigations provide benefit to patients with CRS following ESS. Overall it appears that short-term use of topical high volume budesonide sinonasal irrigations is likely safe, however, all studies evaluated relatively low doses of budesonide (max dose was $1 \mathrm{mg}$ per day) and for short durations (longest duration was 8 weeks). Therefore, future larger controlled trials are needed to improve the level of evidence for effectiveness and to assess the safety of higher doses and longer-term therapy of budesonide irrigations in patients with CRS.

\section{References}

1. Chen Y, Dales R, Lin M (2003) The epidemiology of chronic rhinosinusitis in Canadians. Laryngoscope 113: 1199-1205.

2. Anand VK (2004) Epidemiology and economic impact of rhinosinusitis. Ann Otol Rhinol Laryngol Suppl 193: 3-5.

3. Rudmik L, Smith TL (2011) Quality of life in patients with chronic rhinosinusitis Curr Allergy Asthma Rep 11: 247-252.

4. Alt JA, Smith TL (2013) Chronic rhinosinusitis and sleep: a contemporary review. Int Forum Allergy Rhinol 3: 941-949.

5. Soler ZM, Mace J, Smith TL (2008) Symptom-based presentation of chronic rhinosinusitis and symptom-specific outcomes after endoscopic sinus surgery. Am J Rhinol 22: 297-301.

6. Rank MA, Wollan P, Kita H, Yawn BP (2010) Acute exacerbations of chronic rhinosinusitis occur in a distinct seasonal pattern. J Allergy Clin Immunol 126: 168-169.

7. Chester AC, Sindwani R, Smith TL, Bhattacharyya N (2008) Systematic review of change in bodily pain after sinus surgery. Otolaryngol Head Neck Surg 139 759-765.

8. Rudmik L, Smith TL, Schlosser RJ, Hwang PH, Mace JC, et al. (2014)Productivity costs in patients with refractory chronic rhinosinusitis. Laryngoscope .

9. Bhattacharyya N (2011) Incremental health care utilization and expenditures for chronic rhinosinusitis in the United States. Ann Otol Rhinol Laryngol 120 423-427. 
Citation: Rudmik L (2014) High Volume Sinonasal Budesonide Irrigations for Chronic Rhinosinusitis: An Update on the Safety and Effectiveness. Adv Pharmacoepidemiol Drug Saf 3: 148. doi:10.4172/2167-1052.1000148

Page 5 of 5

10. Fokkens WJ, Lund VJ, Mullol J, Bachert C, Alobid I, et al. (2012) EPOS 2012 European position paper on rhinosinusitis and nasal polyps 2012. A summary for otorhinolaryngologists. Rhinology 50: 1-12.

11. Poetker DM, Jakubowski LA, Lal D, Hwang PH, Wright ED, et al. (2013) Oral corticosteroids in the management of adult chronic rhinosinusitis with and without nasal polyps: an evidence-based review with recommendations. Int Forum Allergy Rhinol 3:104-120.

12. Rudmik L, Hoy M, Schlosser RJ, Harvey RJ, Welch KC, et al. (2013) Topical therapies in the management of chronic rhinosinusitis: an evidence-based review with recommendations. Int Forum Allergy Rhinol 3: 281-298.

13. Soler ZM, Oyer SL, Kern RC, Senior BA, Kountakis SE, et al. (2013) Antimicrobials and chronic rhinosinusitis with or without polyposis in adults an evidenced-based review with recommendations. Int Forum Allergy Rhinol 3: $31-47$

14. Wentzel JL, Soler ZM, DeYoung K, Nguyen SA, Lohia S, et al. (2013) Leukotriene antagonists in nasal polyposis: a meta-analysis and systematic review. Am J Rhinol Allergy 27: 482-489.

15. Rudmik L, Mace J, Soler ZM, Smith TL (2014) Long-term utility outcomes in patients undergoing endoscopic sinus surgery. Laryngoscope 124: 19-23.

16. Soler ZM, Wittenberg E, Schlosser RJ, Mace JC, Smith TL (2011) Health state utility values in patients undergoing endoscopic sinus surgery. Laryngoscope 121: $2672-2678$

17. Harvey RJ, Goddard JC, Wise SK, Schlosser RJ (2008) Effects of endoscopic sinus surgery and delivery device on cadaver sinus irrigation. Otolaryngol Head Neck Surg 139: 137-142.

18. Snidvongs K, Kalish L, Sacks R, Sivasubramaniam R, Cope D, et al. (2013) Sinus surgery and delivery method influence the effectiveness of topical corticosteroids for chronic rhinosinusitis: systematic review and meta-analysis. Am J Rhinol Allergy 27: 221-233.

19. Harvey RJ, Debnath N, Srubiski A, Bleier B, Schlosser RJ (2009) Fluid residuals and drug exposure in nasal irrigation. Otolaryngol Head Neck Surg 141: 757-761.

20. Bleier BS, Debnath I, Harvey RJ, Schlosser RJ (2011) Temporospatia quantification of fluorescein-labeled sinonasal irrigation delivery. Int Forum Allergy Rhinol 1: 361-365.

21. Miller TR, Muntz HR, Gilbert ME, Orlandi RR (2004) Comparison of topica medication delivery systems after sinus surgery. Laryngoscope 114: 201-204.

22. Thomas WW 3rd, Harvey RJ, Rudmik L, Hwang PH, Schlosser RJ (2013) Distribution of topical agents to the paranasal sinuses: an evidence-based review with recommendations. Int Forum Allergy Rhinol 3: 691-703.

23. Kalish L, Snidvongs K, Sivasubramaniam R, Cope D, Harvey RJ (2012) Topical steroids for nasal polyps. Cochrane Database Syst Rev 12: CD006549.

24. Rudmik L, Schlosser RJ, Smith TL, Soler ZM (2012) Impact of topical nasal steroid therapy on symptoms of nasal polyposis: a meta-analysis. Laryngoscope 122: $1431-1437$.

25. Snidvongs K, Kalish L, Sacks R, Craig JC, Harvey RJ (2011) Topical steroid for chronic rhinosinusitis without polyps. Cochrane Database Syst Rev CD009274.

26. Selroos O, Edsbäcker S, Hultquist C (2004) Once-daily inhaled budesonide for the treatment of asthma: clinical evidence and pharmacokinetic explanation. $J$ Asthma 41: 771-790.

27. AstraZeneca Inc.: Pulmicort Respules.

28. Sandoz Inc.

29. Horowitz E, Bergman LC2, Ashkenazy C3, Moscona-Hurvitz 14, Grinvald-Fogel $\mathrm{H} 2$, et al. (2014) Off-label use of sodium valproate for schizophrenia. PLoS One 9: e92573.
30. Actavis Inc.

31. Pulmicort Respules (budesonide inhalation suspension): Highlights of Prescribing Information.

32. Jang DW, Lachanas VA, Segel J, Kountakis SE (2013) Budesonide nasa irrigations in the postoperative management of chronic rhinosinusitis. Int Forum Allergy Rhinol 3: 708-711.

33. Nader ME, Abou-Jaoude P, Cabaluna M, Desrosiers M (2010) Using response to a standardized treatment to identify phenotypes for genetic studies of chronic rhinosinusitis. J Otolaryngol Head Neck Surg 39: 69-75.

34. Rotenberg BW, Zhang I, Arra I, Payton KB (2011) Postoperative care for Samter's triad patients undergoing endoscopic sinus surgery: a double-blinded, randomized controlled trial. Laryngoscope 121: 2702-2705

35. Snidvongs K, Pratt E, Chin D, Sacks R, Earls P, et al. (2012) Corticosteroid nasal irrigations after endoscopic sinus surgery in the management of chronic rhinosinusitis. Int Forum Allergy Rhinol 2: 415-421.

36. Steinke JW, Payne SC, Tessier ME, Borish LO, Han JK, et al. (2009) Pilot study of budesonide inhalant suspension irrigations for chronic eosinophilic sinusitis. J Allergy Clin Immunol 124: 1352-1354.

37. Allen DB (2000) Systemic effects of intranasal steroids: an endocrinologist's perspective. J Allergy Clin Immunol 106: S179-190.

38. Demoly P (2008) Safety of intranasal corticosteroids in acute rhinosinusitis. Am J Otolaryngol 29: 403-413.

39. Poetker DM1, Smith TL (2012) What rhinologists and allergists should know about the medico-legal implications of corticosteroid use: a review of the literature. Int Forum Allergy Rhinol 2: 95-103.

40. Welch KC, Thaler ER, Doghramji LL, Palmer JN, Chiu AG (2010) The effects of serum and urinary cortisol levels of topical intranasal irrigations with budesonide added to saline in patients with recurrent polyposis after endoscopic sinus surgery. Am J Rhinol Allergy 24: 26-28.

41. Bhalla RK, Payton K, Wright ED (2008) Safety of budesonide in saline sinonasa irrigations in the management of chronic rhinosinusitis with polyposis: lack of significant adrenal suppression. J Otolaryngol Head Neck Surg 37: 821-825.

42. Seiberling KA, Chang DF, Nyirady J, Park F, Church CA (2013) Effect of intranasal budesonide irrigations on intraocular pressure. Int Forum Allergy Rhinol 3: 704-707.

43. Gluck PA, Gluck JC (2005) A review of pregnancy outcomes after exposure to orally inhaled or intranasal budesonide. Curr Med Res Opin 21: 1075-1084.

44. FDA Pregnancy Categories.

45. Christensson C, Thoren A, Lindberg B (2008) Safety of inhaled budesonide: clinical manifestations of systemic corticosteroid-related adverse effects. Drug Saf 31: 965-988. 